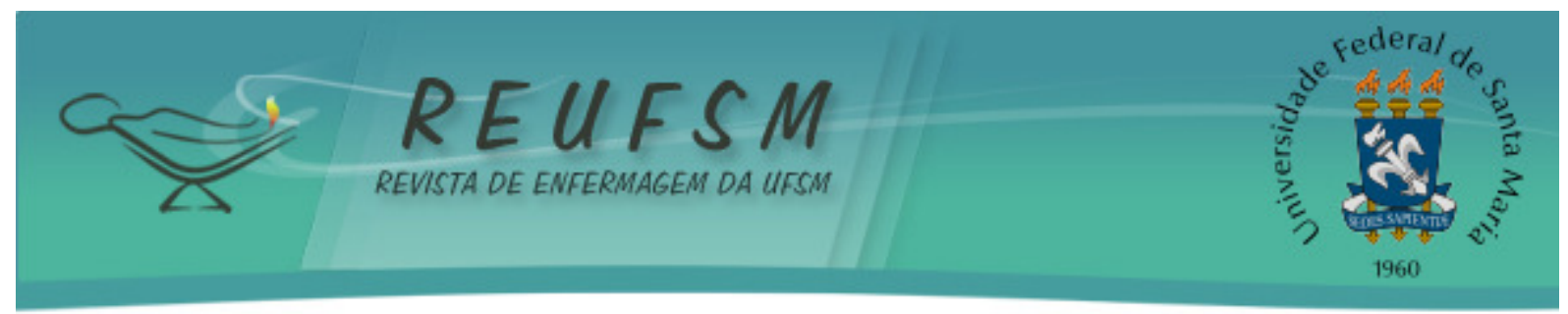

ARTIGO ORIGINAL

\title{
CUIDADO A PESSOAS COM DEPENDÊNCIA QUÍMICA EM HOSPITAL GERAL NA ÓTICA DA EQUIPE DE ENFERMAGEM
}

\author{
CARE TO PEOPLE WITH CHEMICAL DEPENDENCE IN A GENERAL HOSPITAL BY \\ NURSING GROUP VIEW
}

\section{ATENCIÓN A PERSONAS CON DEPENDENCIA QUÍMICA EN HOSPITAL GENERAL EN LA PERSPECTIVA DEL EQUIPO DE ENFERMERÍA}

Doi: $10.5902 / 217976927998$

\author{
Juline Aparecida dos Santos Henriques ${ }^{1}$ \\ Leila Mariza Hildebrandt ${ }^{2}$ \\ Marinês Tambara Leite ${ }^{3}$ \\ Isabel Cristina Pacheco Van der Sand ${ }^{4}$
}

RESUMO: Objetivo: identificar a concepção de profissionais de enfermagem sobre o cuidado
a pessoas dependentes de substâncias psicoativas internadas em hospital geral. Método:
estudo descritivo, qualitativo, que envolveu profissionais de enfermagem vinculados a um
hospital geral de pequeno porte. Na coleta de dados foi utilizada a entrevista
semiestruturada. A análise dos dados seguiu os passos da análise temática. Resultados: após
a análise dos dados, emergiu um tema que versa sobre o cuidado ao indivíduo dependente de
substâncias psicoativas no hospital geral. Conclusão: há preocupação da enfermagem em
realizar intervenções adequadas às demandas do paciente, de forma qualificada, na
expectativa de que o indivíduo possa melhorar e retomar o seu cotidiano. Descritores: Cuidados de enfermagem; Saúde mental; Transtornos relacionados ao uso de substâncias; Equipe de enfermagem; Hospitais gerais.

ABSTRACT: Aim: to identify the professional's conception of nursing about the care to substance-dependent people admitted to a general hospital. Method: descriptive study, qualitative that involved eighteen professionals from nursing to a small general hospital. In searching for dates was used the interview part structured. The analysis of the dates followed to the thematic analysis. Results: after analyzing the data, a theme emerged that focuses on the care to the individual dependent of psychoactive substances in the general hospital. Conclusion: there is a worry from the nursing in accomplished the right interventions to the demands from the patient in a qualify way in the expectation that the person could get better and return to their routine.

Descriptors: Nursing care; Mental health; Substance related disorders; Nursing team; Hospitals general.

\footnotetext{
${ }^{1}$ Enfermeira vinculada à Estratégia de Saúde da Família do Município de Itapejara D’Oeste/PR, egressa do Curso de Enfermagem da Universidade Federal de Santa Maria/Campus de Palmeira das Missões/RS, Brasil. E-mail: juline.henriques@hotmail.com

${ }^{2}$ Enfermeira, Doutoranda do Curso de Pós-Graduação Dinter Novas Fronteiras da UNIFESP, UFRJ e UFSM, Docente do Curso de Enfermagem da Universidade Federal de Santa Maria/Campus de Palmeira das Missões/RS, Brasil. E-mail: leilahildebrandt@yahoo.com.br

${ }^{3}$ Enfermeira, Dra em Gerontologia pela PUC/RS, Docente do Curso de Enfermagem da Universidade Federal de Santa Maria/Campus de Palmeira das Missões/RS, Tutora do Grupo PET Enfermagem de Palmeira das Missões/RS, Brasil. E-mail: tambaraleite@yahoo.com.br

${ }^{4}$ Enfermeira, Doutoranda do Curso de Pós-Graduação Dinter Novas Fronteiras da UNIFESP, UFRJ e UFSM, Docente do Curso de Enfermagem da Universidade Federal de Santa Maria/Campus de Palmeira das Missões/RS, Brasil. E-mail: isabelvan@gmail.com
} 


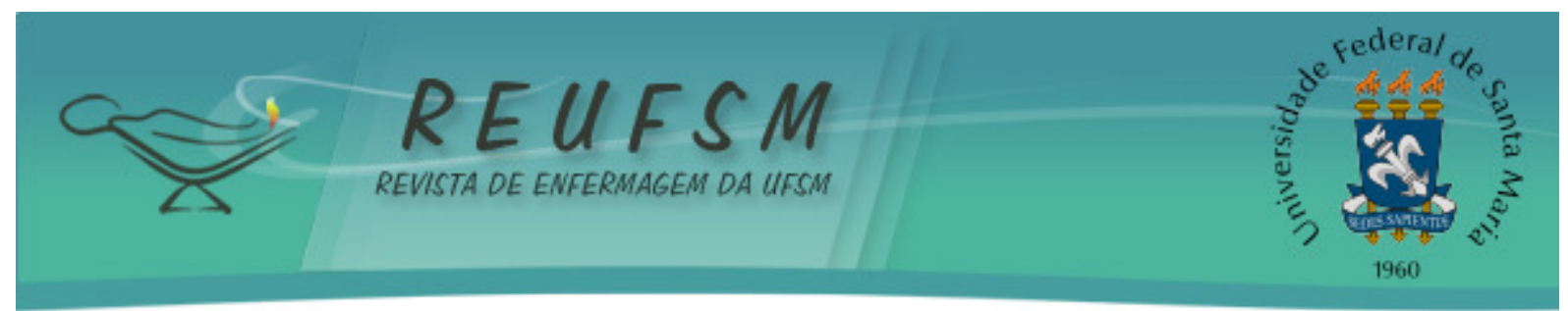

RESUMEN: Objetivo: identificar la concepción de los profesionales de enfermería sobre el cuidado a personas dependientes de substancias psicoactivas internadas en hospital general. Método: estudio descriptivo, cualitativo, que involucro profesionales de enfermería vinculados a un hospital general. En la recolección de los datos, fue utilizada encuesta semiestructurada. En el análisis de los datos siguió los pasos del análisis temático. Resultados: después de analizar los datos, un tema que surgió se centra en el cuidado al individuo dependiente de sustancias psicoactivas en el hospital general. Conclusión: hay preocupación del área de enfermería en realizar intervenciones adecuadas a las demandas del paciente, de forma calificada, en la expectativa de que el individuo pueda mejorar y retomar su cuotidiano.

Descriptores: Atención de enfermería; Salud mental; Trastornos relacionados con sustâncias; Grupo de enfermería; Hospitales generales.

\section{INTRODUÇÃO}

Atualmente, a dependência química se constitui em uma questão social que compromete o usuário de substâncias psicoativas, sua família e a sociedade. No passado, os transtornos relacionados ao uso de substâncias eram atribuídos a populações menos favorecidas socioeconomicamente, hoje eles se revelam como um processo homogêneo, presente no cenário social, sem restrições de classe socioeconômica, cor, credo ou cultura. ${ }^{1}$

Nesse contexto, o consumo de drogas se mostra como um dos fatores de relevância na desorganização individual, familiar e social da pessoa dependente química. Além disso, representa um elevado custo socioeconômico e sanitário, pois o início do uso de substâncias psicoativas por pessoas mais jovens é cada vez mais frequente. Pesquisa, cujo objetivo foi caracterizar o perfil de dependentes químicos atendidos em uma unidade de reabilitação de um hospital psiquiátrico, identificou que a maior parte se encontrava em uma faixa etária economicamente ativa (37\% com idade entre 26 e 37 anos e $16 \%$ entre 18 e 25 anos), $77 \%$ perderam o emprego pelo menos uma vez em função do uso de drogas e 80\% tiveram episódios de separação relacionada a mesma condição. ${ }^{2}$

As substâncias psicoativas atuam diretamente no sistema nervoso central (SNC), causam alterações de comportamento, de humor, de cognição e de percepção e podem ser de uso lícito ou ilícito. ${ }^{3}$ Os critérios para diagnóstico de dependência química incluem tolerância, presença de sinais e sintomas de abstinência e esforço ineficaz no sentido de reduzir ou controlar seu uso. ${ }^{4}$ A pessoa dependente, com frequência, está diante de uma realidade que the parece insuportável, não se sente em condições de modificá-la e entende que a transformação desse contexto pode se dar com o uso de substâncias psicoativas. ${ }^{5}$

Nesse ínterim, os hospitais gerais se constituem em lócus de intervenção no campo da saúde e necessitam articular-se com os demais serviços que compõem a rede de atenção em saúde mental, de modo que sua ação ultrapasse o espaço hospitalar. Assim, o Ministério da Saúde tem incentivado a ampliação e a criação de novos leitos em hospitais gerais para a atenção integral às pessoas dependentes de álcool e outras drogas. ${ }^{6}$

Estudo, realizado a partir de pesquisa documental com 203 prontuários de pessoas que internaram em uma unidade psiquiátrica de hospital geral, indica um crescente aumento das internações de indivíduos com transtornos atrelados ao uso de drogas, em especial álcool, com $76,3 \%$ dos casos. 0 período de internação variou de quatro a 15 dias e as condições que justificaram a procura pelo hospital estavam relacionadas à síndrome de abstinência alcoólica $(55,7 \%)$, risco de complicações $(12,3 \%)$ e necessidade de tratamento psiquiátrico $(9,4 \%){ }^{7}$

No cenário da internação psiquiátrica em hospital geral, ressalta-se a importância do trabalho desenvolvido por equipes que atuam de forma inter e transdisciplinar. Nesse contexto, se insere a enfermagem, cuja essência de seu trabalho é o cuidado. No caso da pessoa 


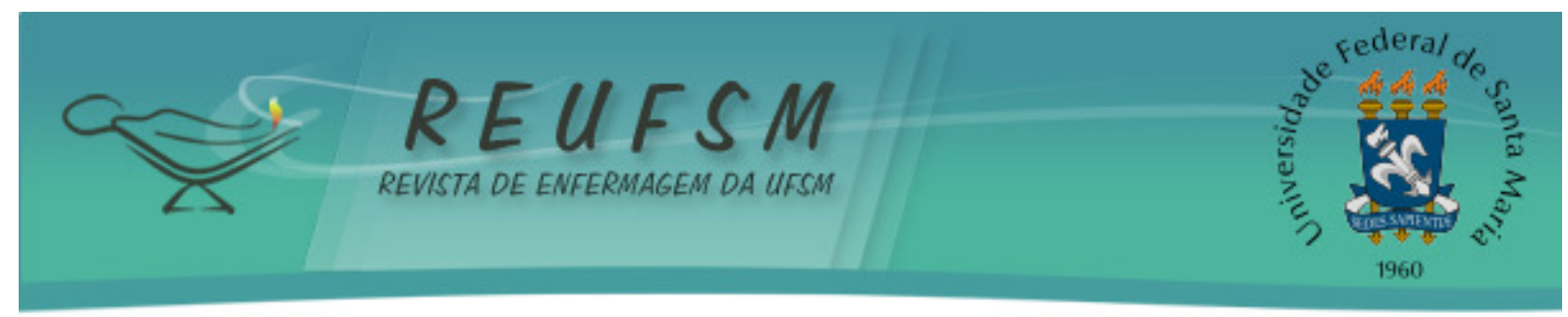

dependente de substâncias psicoativas, a intervenção de enfermagem envolve a escuta, o acolhimento, o cuidado aos aspectos físicos e psíquicos, bem como o suporte à família.

Sabe-se que a internação hospitalar não se constitui no tratamento exclusivo para a pessoa dependente de substâncias psicoativas, mas em uma estratégia de enfrentamento da dependência, com vistas a promover a abstinência inicial do uso de drogas e tratar as complicações oriundas dela, sejam elas de ordem física ou psíquica. ${ }^{8}$ Por isso, os profissionais de enfermagem precisam estar qualificados para atender essa demanda e incentivar o sujeito dependente a prosseguir no tratamento ambulatorial após a alta.

Dessa maneira, destaca-se a importância do cuidado de enfermagem já que o hospital geral se constitui em um dos espaços de intervenção junto à pessoa com dependência química, comumente com o propósito de desintoxicar e tratar as complicações decorrentes dela.

Em vista disso, a pergunta que norteou a pesquisa é: Qual a concepção da equipe de enfermagem em relação ao cuidado da pessoa dependente de substâncias psicoativas que se encontra internada em hospital geral? Assim, o presente estudo tem como objetivo identificar a concepção de profissionais de enfermagem sobre o cuidado à pessoa dependente de substâncias psicoativas internadas em um hospital geral.

\section{MÉTODO}

Estudo descritivo de abordagem qualitativa, realizado em um hospital geral de pequeno porte, localizado na região noroeste do Rio Grande do Sul/Brasil. A referida instituição hospitalar conta um total de 42 leitos, 16 deles destinados à internação de indivíduos com transtornos mentais (11 para pessoas dependentes de substâncias psicoativas e cinco para outras enfermidades psiquiátricas). Os leitos psiquiátricos situamse em unidade aberta de internação clínica.

Os sujeitos da pesquisa foram profissionais de enfermagem (enfermeiros, técnicos e auxiliares de enfermagem) que atuam nos três turnos de trabalho do referido hospital. Os critérios de inclusão para participar do estudo foram: ser profissional de enfermagem e exercer suas atividades em um dos turnos na instituição hospitalar selecionada como campo de coleta de dados. Estar em férias ou em licença de saúde e não aceitar participar do estudo se constituíram em critérios de exclusão. Dos 22 profissionais da equipe de enfermagem, 18 participaram do estudo, destes três enfermeiras, 12 técnicos e três auxiliares de enfermagem, de ambos os sexos, com idades entre 23 e 59 anos. Dos quatro profissionais que não participaram do estudo, dois estavam em férias e dois não aceitaram se integrar a pesquisa. 0 tempo de atuação na instituição varia de dois meses a 29 anos.

Os dados foram coletados de fevereiro a março de 2010, por meio de entrevista semiestruturada, gravada e, após, transcritas na íntegra, a partir das seguintes questões balizadoras: Como se dá a recepção do paciente portador de dependência química no hospital? Como é o cuidado a esse sujeito no decorrer da internação hospitalar? 0 que você pensa acerca da internação de pessoas dependentes de substâncias psicoativas em hospital geral?

A análise dos dados seguiu a proposta de análise temática, ${ }^{9}$ que envolveu a ordenação dos dados, sua classificação e análise final. A fase da ordenação dos dados compreendeu a reunião do material gravado, a transcrição das entrevistas, a leitura e a releitura do material e a organização dos relatos em uma determinada ordem. $\mathrm{Na}$ classificação dos dados, se fez leituras exaustivas e repetidas das informações obtidas no campo empírico da pesquisa, buscando identificar os aspectos relacionados ao tema do estudo e, com isso, construir a temática. $\mathrm{Na}$ análise final, se realizou a articulação entre os dados obtidos junto aos sujeitos do estudo e a revisão da literatura, respondendo a questão da pesquisa, levando em consideração o seu objetivo. ${ }^{9}$ 


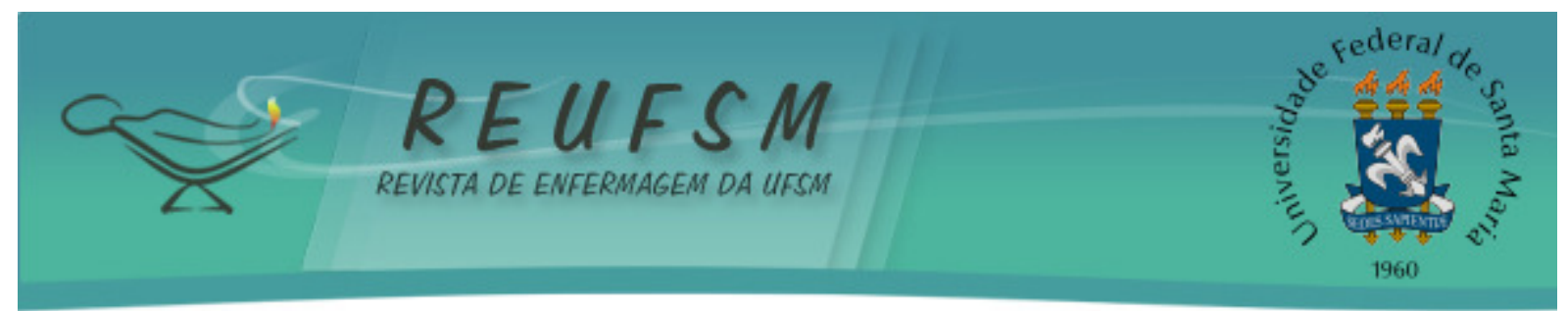

Os procedimentos éticos deste estudo foram observados, de acordo com a Resolução 196/96 do Ministério da Saúde. ${ }^{10}$ Todos os profissionais de enfermagem foram convidados a participar do estudo e, na medida em que houve o aceite, os mesmos assinaram o Termo de Consentimento Livre e Esclarecido. 0 projeto de pesquisa foi aprovado pelo Comitê de Ética em Pesquisa da Universidade Federal de Santa Maria (UFSM), mediante processo $n^{\circ}$ 23081.014585/2009-34.

\section{RESULTADOS E DISCUSSÃO}

Da análise dos dados emergiu uma unidade temática que trata da concepção dos profissionais de enfermagem sobre o cuidado ao indivíduo dependente de substâncias psicoativas internado em hospital geral.

0 cuidado ao indivíduo usuário de substâncias psicoativas no hospital geral: o que dizem os profissionais de enfermagem

Por sua vez esta temática foi subdividida em três subtemáticas. A primeira aborda aspectos relativos ao acolhimento da pessoa dependente de substâncias psicoativas em hospital geral. A segunda discute o cuidado prestado pela enfermagem durante a hospitalização e a terceira versa acerca das dificuldades da enfermagem na prestação do cuidado a esse contingente populacional.

\section{0 acolhimento}

Vários elementos emergiram no discurso dos sujeitos do estudo acerca dos cuidados à pessoa dependente de substâncias psicoativas internada em hospital geral. Um dos aspectos diz respeito ao momento da internação hospitalar. Os profissionais de enfermagem falam em diferenças na forma de receber os pacientes e apontam que essa intervenção tem relação com as suas condições clínicas e/ou psíquicas.

Depende do estado como ele chega. Se ele chega fissurado, em surto psicótico ou alguma alteração do estado emocional dele. (E 7)

Considerar o estado mental da pessoa que chega à instituição hospitalar é necessário uma vez que, a partir desse pressuposto, tem-se a opção de utilizar abordagens que melhor se adéquam às condições e demandas da mesma, naquele momento. Em relação a esses aspectos, os entrevistados expressam o modo de intervenção diante de um paciente quando este está tranquilo ou com agitação psicomotora, como pode ser visualizado no exemplo a seguir.

Porque têm aqueles que vêm de livre e espontânea vontade, ele não usou pelo menos nas últimas 24 horas. É um paciente mais calmo, que tu pode conversar, fazer a abordagem, encaminhar para o leito, tem mais tranquilidade. E tem o paciente que já chega por via judicial ou ele vem forçado de uma forma ou outra, ou pelo familiar ou por " $n$ " motivos. Ele acaba vindo sem querer. Então esse é um pouquinho mais difícil, ele já vem agressivo, cheio de "quatro pedras na mão" para atirar na enfermagem. É um mais complicado. (E 1)

Entende-se que, de certa forma, a agitação psicomotora pode culminar em um quadro de agressividade (tanto verbal quanto física) e, assim, amedrontar os integrantes da equipe. 


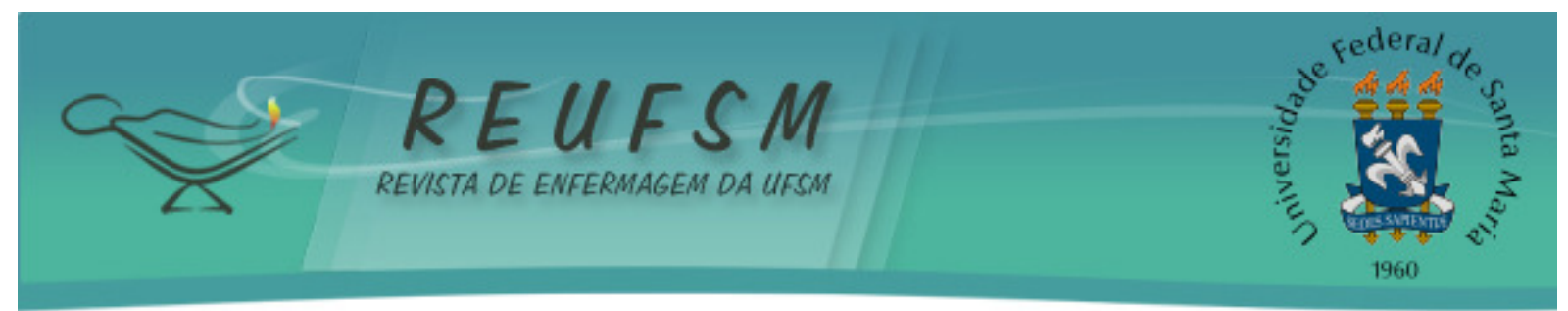

Ressalta-se que sentimentos de medo e raiva frequentemente são experimentados pelos profissionais em situações de emergências psiquiátricas, entretanto os mesmos devem estar atentos para evitar que suas intervenções sejam excessivamente permissivas ou punitivas. ${ }^{11}$

Um dos participantes da investigação, ao se referir à atenção destinada ao paciente no momento em que ele é acolhido, faz uma crítica em relação à falta de preparo e qualificação da equipe, o que pode alimentar o receio na abordagem da pessoa dependente de substâncias psicoativas.

Quando é um dependente químico sempre com receio, porque eu particularmente nunca recebi algum treinamento para trabalhar com esse tipo de paciente. (E 16)

Nos serviços de saúde, é necessário estar constantemente discutindo, com base em teorias, acerca de temas relacionados à prática. Quando se trata de intervenções junto a pessoas portadoras de transtornos mentais, a qualificação dos profissionais é essencial até porque ainda perpassa no cotidiano a noção de periculosidade e imprevisibilidade do indivíduo acometido por alguns transtornos mentais, incluindo a dependência química. Entende-se que a realização de encontros de qualificação entre os trabalhadores de enfermagem na própria instituição e a participação em eventos científicos contribuem para a troca de experiências e o fortalecimento do conhecimento científico e prático dos trabalhadores, preocupação também apontada em estudos com profissionais da atenção básica em outras regiões do país. ${ }^{12}$

Os entrevistados, ainda, levantam a maneira como se dá o cuidado no momento da chegada do paciente ao hospital, como exemplificado abaixo.

Primeiramente, a gente faz uma abordagem, recebe esse paciente lá na recepção, tenta encaminhar ao leito, explicar a rotina sempre com o familiar junto e vai medicar conforme a prescrição do médico assistente. Mas se ele estiver em surto, muitas vezes, é preciso conter, precisa chamar mais colegas para usar a força mesmo, mas tudo para o bem do paciente, para ele não se autoagredir e também não nos agredir. (E 7)

Compreende-se que o acolhimento do paciente na instituição exerce um papel fundamental em relação à adesão deste ao tratamento. 0 cuidar em saúde mental consiste em acolher o sujeito, que tem um comportamento diferente, interagir com ele, possibilitando ao mesmo alternativas de expressão. ${ }^{12}$ Todavia, além de acolher 0 indivíduo que possui uma história de vida, em que a dependência química faz parte dela, a equipe de enfermagem precisa oferecer intervenções que atendam as suas demandas de forma integral.

\section{Cuidados de enfermagem à pessoa com dependência química na internação hospitalar}

Após a internação do indivíduo, dependente de substâncias psicoativas, o cuidado varia de acordo com o seu comportamento e com as manifestações clínicas apresentadas no período de desintoxicação.

Os primeiros dias quando eles chegam, eles estão calmos. Depois eles entram em abstinência, que é aí que tem que tomar bastante cuidado. Tem que dar sempre muita atenção para eles, porque essa fase é bem crítica, a fase em que eles começam com aquela 


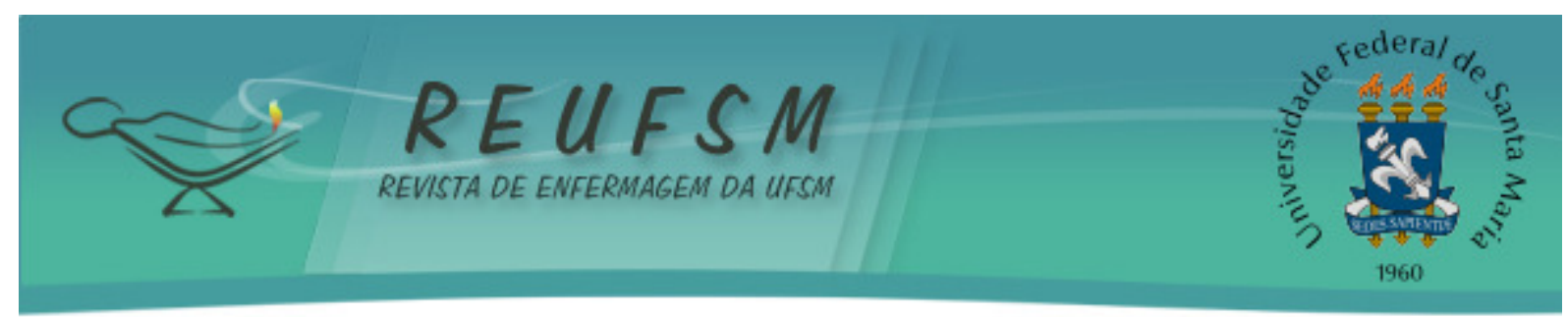

abstinência, a falta da droga. Ás vezes tem que medicar, às vezes tem que conter o paciente. (E 5)

Usualmente, após a interrupção do uso de substâncias psicoativas, a pessoa apresenta sintomas de abstinência. Sua gravidade depende do tipo, quantidade e tempo de uso da droga. A abstinência compreende sintomas físicos e psíquicos de desconforto frente à redução ou interrupção do consumo. Inicialmente, são predominantes manifestações psíquicas como fissura pela droga, ansiedade, sintomas depressivos, irritação, déficit de concentração e insônia. De forma mais grave, podem surgir sinais físicos, tais como: tremor, suor difuso, palpitações cardíacas, aumento da temperatura corporal, náuseas e vômitos, podendo chegar a quadros de desagregação mental (delirium). ${ }^{5,13}$ enfermagem.

No período de abstinência, há a necessidade de cuidado redobrado por parte da

Orientar os dependentes químicos na questão de que quando eles começam a ter fissura, deixar bem aberto para eles virem nos falar, eles tem que vir aqui no posto e pedir medicação. (E 1)

As intervenções de enfermagem incluem àquelas de caráter biológico, neste caso, mais voltadas ao processo de desintoxicação e alívio de sintomas físicos e, também, as de caráter psicológico, por meio de suporte e estímulos à pessoa doente, reforçando suas potencialidades. Estudo realizado com dependentes de crack evidenciou que, mesmo com as consequências dessa enfermidade na vida das pessoas, esses indivíduos são capazes de descrever os cuidados profissionais que entendem como necessários para sua recuperação. Assim, destacam um bom relacionamento interpessoal, a possibilidade de livre expressão de sentimentos e, além disso, afeto, cortesia, respeito e atenção por parte dos profissionais. ${ }^{14}$

Dos dados emerge também a relevância em atentar para a evolução (ou involução) da condição clínica dos pacientes durante o tratamento.

Têm pacientes que tu tem que estar mais atenta, se eles estão tomando a medicação, se o tratamento está tendo uma evolução boa, tu tens que prestar atenção assim, no tempo que eles estão, se eles tão melhorando ou não. (E 9)

Percebe-se a preocupação profissional na adesão do paciente ao tratamento que está sendo ofertado. Isso, provavelmente, tem relação com o fato de que muitos têm dificuldade em aceitar sua condição de dependentes químicos. Para que haja uma boa adesão ao tratamento é necessário que eles tenham a possibilidade de participar ativamente do processo terapêutico e que sejam escutados de modo ativo pelo profissional de saúde que os atendem. ${ }^{15}$

Em relação aos cuidados prestados ao dependente químico, ainda no decorrer da internação, um dos entrevistados coloca que não há conversa com o paciente durante o período em que ele se encontra contido mecanicamente.

Se o paciente está contido não tem o que tu conversar, faz a medicação, mais tarde a gente conversa com a família. (E 2)

Entende-se que, embora o paciente tenha dificuldade em assimilar as informações e manter um diálogo no momento em que está contido mecanicamente, a equipe de enfermagem deve ter uma atitude de tolerância, compreensão e manter uma conversa explicativa, favorecendo o relacionamento, a aceitação da medida adotada e o entendimento por parte do paciente. 


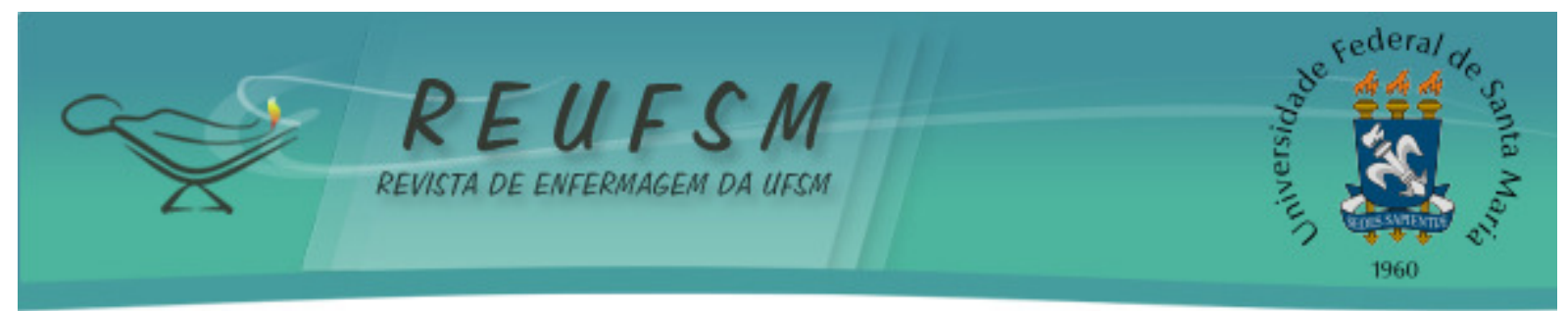

A contenção mecânica, embora ainda seja contestada como método terapêutico, por vezes é necessária, em especial, nas situações de agressividade em que há risco para o paciente, equipe ou família. Entretanto sua realização requer o manejo verbal e a contenção química anterior, a preservação da segurança e do conforto do paciente, a avaliação contínua da equipe de saúde e a manutenção da contenção mecânica pelo menor tempo possível. ${ }^{11}$

Outro dado apontado como meio de tratamento consiste na participação do dependente químico em diversas atividades, que são ofertadas e realizadas na própria instituição. Estas são desenvolvidas na modalidade de oficinas, grupos e sessões de cinema. Destaca-se que algumas delas são coordenadas e acompanhadas pelos profissionais da equipe de enfermagem.

Eles têm pátio para descer, tem atividade, tem socialização de manhã e de tarde. Têm cinema, reuniões e palestras de grupos de dependentes químicos. (E 1)

O desenvolvimento de tais atividades durante o período de internação é fundamental, principalmente quando é realizado coletivamente, colaborando, entre outros aspectos, no processo de reinserção social deste indivíduo. As oficinas contribuem para o alívio das tensões diárias, além de ter produtos construídos a partir delas que podem dar um reforço à autoestima. ${ }^{16}$

0 que se evidencia por meio de alguns discursos é que o cuidado da equipe de enfermagem se inicia desde o momento de chegada da pessoa à instituição, até a sua alta hospitalar. Esse cuidado se faz presente na realização dos procedimentos, nas orientações, no diálogo e nas observações. Enfim, a interação entre profissionais de enfermagem e pacientes se materializa por uma prática que não se limita apenas aos aspectos biológicos, mas considera o ser humano em sua singularidade, subjetividade e com sentimentos próprios.

Muita conversa, orientação, que geralmente o paciente só toma medicações controladas e quando ele entra em delírio a gente tenta acalmar ele, mais é orientação, conversa, a gente tenta avaliar o paciente na forma física, ver o estado emocional dele, perguntar há quanto tempo ele é dependente químico, logo a seguir a gente faz a entrevista com ele, vê os sinais, o paciente é apresentado ao leito dele. (E 13)

As práticas em saúde requerem novos olhares para o cuidado, baseados no diálogo, nas intervenções e na criatividade, o que possibilita atenção integral ao sujeito enfermo e a sua família. Cuidar é mais que um ato, representa uma atitude que abarca um momento de atenção, de zelo e de desvelo, envolve uma atitude de ocupação, preocupação, de responsabilização e de desenvolvimento afetivo com o outro. ${ }^{17}$

No transcorrer do tratamento também está previsto a inclusão da família no processo de recuperação da pessoa dependente de substâncias psicoativas e construção de vínculo entre a equipe a e família.

A gente procura também conversar bastante com a família, explicar sobre os sintomas da abstinência para o paciente e para a família. Muitos nunca entraram em abstinência, muitas famílias desconhecem as consequências do uso das drogas, o que as drogas afetam no comportamento do paciente e também nas funções psíquicas e emocionais. Não adianta nós falarmos uma linguagem $e$ a família falar outra. E aí a gente tenta, no decorrer do 


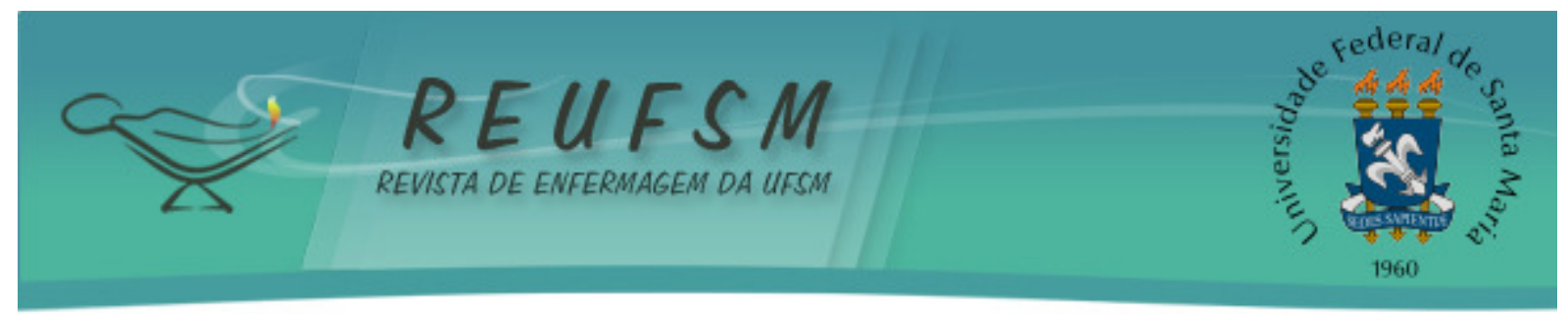

tratamento, estabelecendo esses vínculos, ver coisas que estão fragmentadas, quebradas, principalmente os laços familiares. (E 8)

A família pode ser definida como um grupo de indivíduos interligados por fortes vínculos emocionais e pelo sentimento de pertencer e participar das vidas uns dos outros. ${ }^{18}$ Sendo assim, a dependência química de um dos membros da família, certamente, acarretará em sobrecarga e estresse para todos os seus integrantes. Compreende-se que a atitude de incluí-la no processo de reabilitação do dependente de substâncias psicoativas, instruindo-a por meio de informações, orientações, esclarecimentos representa uma forma de ela poder conseguir adaptar-se a essa situação, priorizando o cuidado de seu familiar doente.

Alguns entrevistados apontam a diminuição do preconceito acerca da dependência de substâncias psicoativas e seu reconhecimento como outra doença, constituindo-se em fator positivo na assistência ao dependente.

Eles pedem bastante atenção, precisa ser uma pessoa que seja calma e tenha consciência de que é uma doença. (E 3)

Eles têm um convívio bom, porque se eles estão em crise, eles ficam no quarto e são medicados lá e é trabalhado até eles melhorarem. Quando eles estão melhores, eles descem para o pátio, conversam com os outros pacientes assim, numa boa. Não tem assim, nenhum preconceito e nem da equipe. (E 7)

Nesse sentido, reforça-se que o trabalho de enfermagem tem como objeto de cuidado o sujeito dependente químico, com vistas a recuperar sua autonomia, restabelecer sua capacidade de gerenciar sua vida e reinseri-lo socialmente. Ressalta-se que a intervenção não está centrada na doença, mas no sujeito inserido em um contexto social, cuja finalidade tem relação com as necessidades de saúde e não mais a remissão dos sintomas exclusivamente. ${ }^{19}$

Outro pesquisado mencionou o fato de a pessoa dependente química estar interagindo dentro da instituição com pessoas acometidas por outras enfermidades, como um aspecto positivo no processo de reinserção social.

Eu vejo que para o paciente dependente é bom o fato de ele poder compartilhar com outras pessoas, que ele possa não se sentir excluído da sociedade, conviver os dias da internação com pacientes que têm outros tipos de doença. (E 12)

Nos hospitais gerais, em que há espaços de menor dimensão, com cerca de dez a trinta leitos, há estímulo à interação entre as pessoas, em contraposição ao que ocorria nos antigos e grandiosos hospitais psiquiátricos, os quais favoreciam prioritariamente o controle e a vigilância. ${ }^{20}$ Nesse cenário, ratifica-se a importância do hospital geral na reabilitação das pessoas com transtornos relacionados ao uso de drogas, com reforço ao resgate da subjetividade e da autonomia desse contingente populacional, além de mantê-lo próximo de seu lugar de convívio.

Dificuldades enfrentadas pela enfermagem no cuidado a pessoa dependente de substâncias psicoativa

Alguns entrevistados encontram dificuldades em cuidar de indivíduos com transtornos relacionados ao uso de substâncias psicoativas dentro do hospital geral. Compreendem que a assistência poderia ser no espaço do hospital geral, mas em uma ala separada dos demais. 


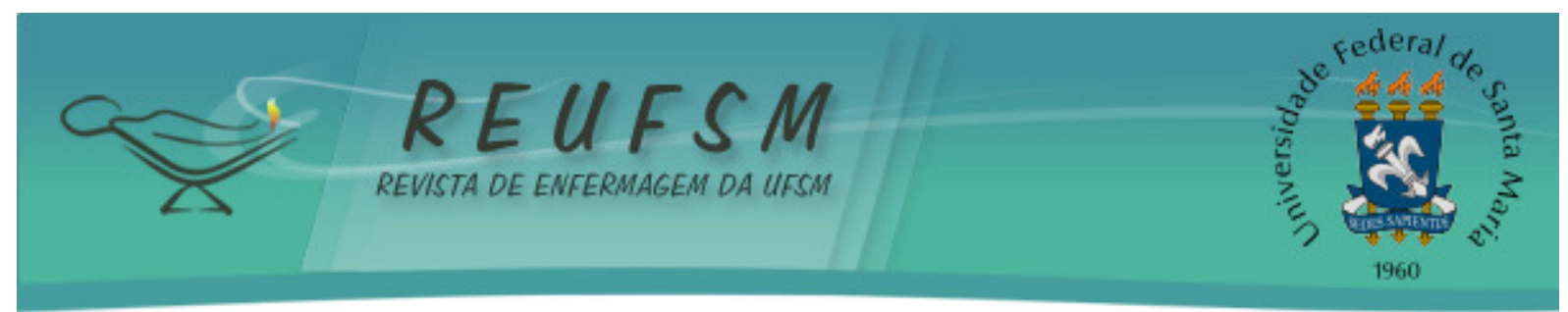

Atribuem o motivo do atendimento de portadores de transtornos mentais, incluindo a dependência química, no mesmo ambiente em que se tratam pacientes com outras patologias, ao fato de o hospital não possuir infraestrutura para atender diferentes especialidades.

Eu acho que teria que ter uma ala separada para pacientes psiquiátricos e dependentes químicos e outra ala para pacientes da clínica geral. Mas aqui no nosso hospital não comporta esse tipo de atendimento, uma ala para um lado e outra para outro. Nesse sentido eu encontro dificuldades de trabalhar. (E 13)

Pode-se identificar como núcleo central desses discursos que, para eles, se a instituição tivesse infraestrutura para comportar alas separadas, o tratamento dos sujeitos com dependência química poderia se dar de forma mais adequada. Compreende-se que, em algumas situações, em especial quando o sujeito encontra-se com comportamento agressivo ou com sintomas graves de abstinência, é necessário separá-lo para sua proteção e dos demais, o que não significa que tenha que ser em unidades separadas. Nessas circunstâncias, mantê-lo em um quarto individual, com poucos estímulos consistem em um cuidado necessário e indicado. ${ }^{21}$ Ressalva-se que os cuidados dos profissionais devem contemplar os aspectos bio-psico-socio-espiritual, cujo objetivo é possibilitar aos usuários segurança e confiança em relação ao seu tratamento e recuperação. ${ }^{22}$

Corroborando, outros entrevistados mencionam que internar na mesma unidade hospitalar, pessoas dependentes químicas e pacientes com patologias clínicas, pode gerar medo, insegurança e dificuldade de convivência.

Paciente clínico não se sente bem com dependente químico. Acham que eles vão incomodar, que é risco para eles. (E 2)

Eu acho que clínico geral geralmente tem outros tipos de medicações, outros comportamento. Se eles ficam junto com esses pacientes que têm um comportamento diferente do deles, eles começam a ficar nervosos, ansiosos, se preocupam com o bem-estar deles, mesmo dentro do hospital. (E 13)

Diante disso, percebe-se que parte dessas preocupações ainda é influenciada pela história da psiquiatria no mundo, a qual determinou o caráter de incurabilidade da loucura, pois se entendia que, com o isolamento, o sujeito pudesse ser recuperado. Entretanto, considera-se que é nesse cenário de confrontos e contradições que existe a possibilidade de se potencializar o processo que visa à abolição do modelo psiquiátrico excludente e segregador, ainda bastante vivenciado pela sociedade, o qual envolve 0 trabalho ativo dos profissionais de enfermagem.

\section{CONCLUSÃO}

O fenômeno da dependência química envolve muitas variáveis, sendo a sociedade o lócus onde se processam as transições de um saber psiquiátrico hegemônico excludente, para uma forma de assistência que valoriza o sujeito portador de enfermidade mental como cidadão. Ressalta-se que este possui direitos e deveres e que enfrenta cotidianamente as consequências de uma sociedade pouco preparada para tratar a questão dos transtornos relacionados ao uso de drogas. É o caso dos trabalhadores de enfermagem, que buscam uma nova forma de reorganização da rede de serviços 


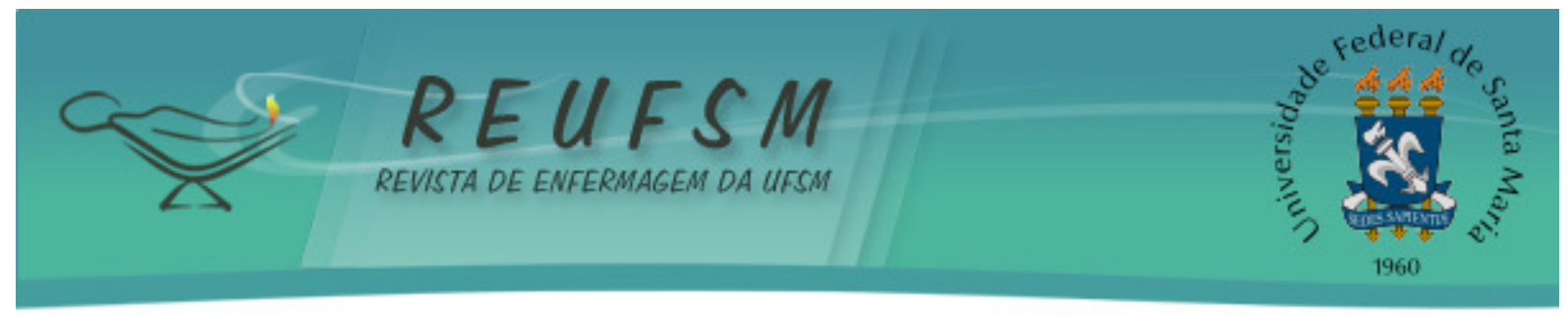

destinada à atenção em saúde mental, em especial ao atendimento a pessoas dependentes químicas em hospitais gerais.

\section{REFERÊNCIAS}

1. Migott AMB. Dependência química: problema biológico, psicológico ou social? Cad Saúde Pública [Internet]. 2008 [acesso 2013 mar 14];24(3):710-11. Disponível em: http://www.scielo.br/pdf/csp/v24n3/27.pdf

2. Silva LHP, Borba LO, Paes MR, Guimarães AN, Mantovani MF, Maftum MA. Perfil dos dependentes químicos atendidos em uma unidade de reabilitação de um hospital psiquiátrico. Esc Anna Nery [Internet] 2010 jul-set [acesso em 2013 set 24];14(3):585-90. Disponível em: http://www.scielo.br/pdf/ean/v14n3/v14n3a21.pdf.

3. Sadock BJ, Sadock VA. Kaplan \& Sadock. Compêndio de psiquiatria: ciência do comportamento e psiquiatria clínica. $9^{\mathrm{a}}$ ed. Porto Alegre: Artmed; 2007. 1584 p.

4. DSM IV TR ${ }^{T M}$. Manual diagnóstico e estatístico de transtornos mentais. $4^{\mathrm{a}}$ ed rev. Porto Alegre: Artmed; 2002. 880 p.

5. Townsend MC. Enfermagem psiquiátrica. $3^{\mathrm{a}}$ ed. Rio de Janeiro: Guanabara Koogan; 2002. 835 p.

6. Brasil. Ministério da Saúde. Secretaria de Atenção à saúde. Coordenação Geral de Saúde Mental, Álcool e Outras Drogas. Saúde Mental no SUS: as novas fronteiras da Reforma Psiquiátrica. Relatório de Gestão 2007-2010 [Internet]. Brasília: Ministério da Saúde; 2011 [acesso $2013 \mathrm{fev}$ 22]. Disponível em: http://portal.saude.gov.br/portal/arquivos/pdf/gestao2007_2010.pdf

7. Sousa FSP, Oliveira EN. Caracterização das internações de dependentes químicos em Unidade de Internação Psiquiátrica do Hospital Geral. Ciênc Saúde Coletiva [Internet]. 2010 [acesso em 2013 mar 14];15(3):671-7. Disponível em: http://www.scielo.br/pdf/csc/v15n3/v15n3a09.pdf

8. Rosenstock KIV, Neves MJ. Papel do enfermeiro da atenção básica de saúde na abordagem ao dependente de drogas em João Pessoa, PB, Brasil. Rev Bras Enferm [Internet]. 2010 [acesso 2013 set 19]; 63(4):581-6. Disponível em: http://www.scielo.br/pdf/reben/v63n4/13.pdf

9. Minayo MCS. O desafio do conhecimento: pesquisa qualitativa em saúde. $12^{\mathrm{a}}$ ed. São Paulo: Hucitec; 2010.

10. Brasil. Ministério da Saúde. Conselho Nacional de Saúde. Resolução n 196/96, de 10 de outubro de 1996. Aprova as seguintes diretrizes e normas regulamentadoras de pesquisa envolvendo seres humanos. Diário Oficial da União, Brasília, 1996 out 10. Seção 1, p. 50-53.

11. Mantovani C, Migon MN, Alheira FV, Del-Bem CM. Manejo de paciente agitado ou agressivo. Rev Bras Psiquiatr [Internet]. 2010 out [acesso 2013 set 24];32 Supl II:S96-S103. Disponível: http://www.scielo.br/pdf/rbp/v32s2/v32s2a06.pdf.

12. Villela SC, Scatena MCM. A enfermagem e o cuidar na área de saúde mental. Rev Bras Enferm. 2004;57(6):738-41.

13. Stuart GW, Laraia MT. Enfermagem psiquiátrica: princípios e prática. $6^{a}$ ed. Porto Alegre: Artmed; 2001. 958 p. 


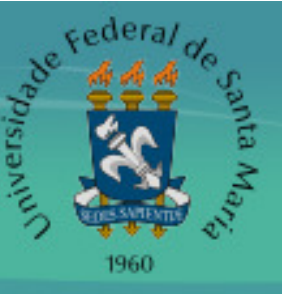

14. Magalhães DEF, Silva MRS. Cuidados requeridos por usuários de crack internados em uma instituição hospitalar. REME Rev Min Enferm [Internet]. 2010 jul-set [acesso em 2013 set 23];14(3):408-15. Disponível em: http://www.enf.ufmg.br/site_novo/modules/mastop_publish/files/files_4d3079563e899.pdf.

15. Scaduto AA, Barbieri V. O discurso sobre a adesão de adolescentes ao tratamento da dependência química em uma instituição de saúde pública. Ciênc Saúde Coletiva [Internet]. 2009 mar-abr [acesso em 2013 set 23];14(2):605-14. Disponível em: http: / / www.scielo.br/scielo.php?script=sci_arttext\&pid=S1413-81232009000200029.

16. Monteiro RL, Loyola CMD. Qualidade de oficinas terapêuticas segundo pacientes. Texto \& contexto enferm [internet]. 2009 [acesso $2013 \mathrm{mar}$ 14];18(3):436-42. Disponível em: http://www.scielo.br/scielo.php?script=sci_arttext\&pid=S0104-07072009000300005.

17. Boff L. Saber cuidar: ética do humano, compaixão pela terra. $18^{\mathrm{a}}$ ed. Petrópolis (RJ): Vozes; 2012. 248 p.

18. Wright LM, Leahey M. Enfermeiras e famílias: um guia para avaliação e intervenção na família. $5^{a}$ ed. São Paulo: Roca; 2012.

19. Barros S, Oliveira MAF, Silva ALA. Práticas inovadoras para o cuidado em saúde. Rev Esc Enferm USP. 2007;41 Esp:815-9.

20. Botega NJ, Dalgalarrondo P. Saúde mental no hospital geral: espaço para o psíquico. $2^{\mathrm{a}}$ ed. São Paulo: Hucitec; 2012. 116 p.

21. Quevedo J, Carvalho AF. Emergências psiquiátricas. 3a ed. Porto Alegre (RS): Artmed; 2013.

22. Siqueira DF, Moreschi C, Pozzobon L, Vedoin PC, Walter RR, Sá RGC. Adolescente usuário de crack: relato de experiência. Rev Enferm UFSM [Internet]. 2012 [acesso em 2013 mar 14];2(2):456-63. Disponível em:

http://cascavel.ufsm.br/revistas/ojs-2.2.2/index.php/reufsm/article/view/3045/3774.

Data de recebimento: $28 / 02 / 2013$

Data de aceite: 16/10/2013

Contato com autor responsável: Leila Mariza Hildebrandt

Endereço: Rua dos Carajás 82, Bairro Pindorama, Ijuí, RS, Brasil. CEP: 98700-000.

E-mail: leilahildebrandt@yahoo.com.br 